\title{
Optimal Investment With Fixed Financing Costs*
}

\author{
Jason G. Cummins \\ Division of Research and Statistics \\ Federal Reserve Board \\ jason.g.cummins@frb.gov \\ Ingmar Nyman \\ Hunter College and the Graduate School \\ The City University of New York \\ ingmar.nyman@hunter.cuny.edu
}

September 8, 2004

\begin{abstract}
Models with a premium on external finance produce counterfactual predictions about liquidity management. We address this shortcoming by introducing a fixed cost of increasing external finance into an otherwise standard investment/financing problem. This additional financial friction is well motivated by case studies and our analysis shows that it generates more realistic predictions about liquidity management: firms hold external finance and idle cash simultaneously, and may invest an additional dollar of cash flow in liquidity rather than repaying external funds or investing in productive capital. In addition to better fitting the stylized facts about the time-series and crosssectional pattern of liquidity holding, these results may help shed light on the fragility of estimates of investment-cash flow sensitivities.
\end{abstract}

JEL Classification: D21, E22, G31.

Keywords: financial adjustment cost; liquidity constraints; corporate cash holdings.

${ }^{*}$ We thank an anonymous referee, R. Gençay (the editor), Steve Bond, and seminar participants at the CUNY Graduate Center, the Federal Reserve Board, Hunter College, and NYU for helpful comments and suggestions. Nyman thanks DELTA and the Stockholm School of Economics for their generous hospitality. The views presented are solely those of the authors and do not necessarily represent those of the Board of Governors of the Federal Reserve System or its staff members. 


\section{Introduction}

Conflicts of interest and asymmetric information make internal and external funds imperfect substitutes. In most models, the resulting financial friction takes the form of an external finance premium. This setup has some intuitive implications, one of which is that the optimal capital stock is decreasing in the amount of external finance (see, for example, Hubbard 1998). But, at the same time, this setup also produces counterfactual predictions about liquidity management: a firm that has outstanding financial obligations cannot hold liquid resources or invest additional cash flow in liquidity.

We address this shortcoming by introducing a fixed cost of acquiring more external finance into an otherwise standard investment/financing problem. This additional financial friction is motivated by evidence that corporate managers feel that the very act of dealing with external financiers is costly. For example, Donaldson's (1984) case studies suggest that corporate managers prefer internal funds because they perceive that external finance carries significant non-pecuniary fixed costs. ${ }^{1}$

Our analysis shows that a fixed financing cost generates more realistic predictions about liquidity management. To avoid paying the fixed cost in the future, firms may hold external finance and idle cash even though the monetary marginal cost of external finance is greater than the marginal return on liquidity. Moreover, firms may invest an additional dollar of cash flow in liquidity rather than repaying external funds or investing in productive capital. In addition to better fitting the stylized facts about the time-series and cross-sectional pattern of liquidity holding, these results may help shed light on the fragility of estimates of investment-cash flow sensitivities (see, for example, Cummins, Hassett, and Oliner 2003, Erickson and Whited 2000).

\footnotetext{
${ }^{1}$ According to Donaldson (1984), "Managers mistrust external sources [of financing] that they could neither predict nor control. In response, they made financial self-sufficiency the central tenet in their financial planning so that the timing, magnitude and form of strategically critical investment remained theirs to decide. In practical terms, this means that they relied on internally generated funds (or retained earnings)." (p. 12)
} 


\section{Model}

Physical capital, $K$, is the sole factor of production. The price of investment is $p$ while the price of output is normalized to unity. Revenue from production in period $t, \Pi\left(K_{t}\right)$, is strictly increasing and strictly concave and satisfies standard boundary conditions. There is a stochastic revenue shock, $z_{t}$, which is additive and independently and identically distributed with a density function $f\left(z_{t}\right)$. As a result, cash flow from operations at time $t$ is the sum of the shock $z_{t}$ and revenue from production $\Pi\left(K_{t}\right)$. The additive uncertainty makes capital a risk-free asset and allows us to contrast the features of our model with a benchmark in which the shock has no effect on the optimal policy. Capital evolves according to the accounting identity: $K_{t+1}=(1-\delta) K_{t}+I_{t}$, where $\delta$ is the constant rate of economic depreciation, and $I$ is investment. Apart from depreciation, investment in capital is completely reversible. Risk and irreversibility can generate inertia in investment, so to focus on the effect of financial frictions, we keep the investment technology free of those complications. $^{2}$

The firm can invest its liquid financial resources, $L$, across periods and earn a rate of return of $i$. The discount factor is therefore $\beta=1 /(1+i)$. Debt, $D$, can be dynamically managed, but to streamline the presentation we assume that equity is trapped inside the firm

— specifically, dividends are set equal to zero until the final period when the shareholders are paid the equity value of the firm. We adopt this simplified treatment of dividends for two reasons. First, our focus is on the trade-off between internal and external sources of financing rather than the on trade-off between different sources of external funds such as debt and equity. Second, corporate payout policy is a poorly understood area of finance. In the absence of a robust and widely-accepted theoretical explanation for dividend payout decisions, we choose to impose an assumption that fits with the key stylized empirical fact about dividends, namely that they are remarkably stable over time. To be sure, we force

\footnotetext{
${ }^{2}$ Worth noting, however, is that capital irreversibility distorts only the investment policy; it cannot by itself generate liquidity holding since repaying expensive debt remains a strictly preferable use of resources.
} 
dividends to be zero, but our results would be qualitatively unaffected if we instead fixed them at a strictly positive level.

The marginal cost of debt, $r\left(D_{t}\right)$, is strictly increasing and strictly convex with $r(0)=$ $i{ }^{3}$ This function is a reduced form that captures the premium creditors charge the firm due to moral hazard or adverse selection problems and could be derived endogenously if we were to assume that shareholders enjoy limited liability. However, we assume no limited liability to economize on space and because little is sacrificed by taking such a shortcut. In particular, limited liability would modify our conclusions in two ways (apart from introducing standard credit risk due to default that would be priced in equilibrium through the $r\left(D_{t}\right)$ function). First, if capital were risky then limited liability would create incentives for excessive risk-taking and the optimal capital stock would be larger in all circumstances. But capital is riskless in our model, so this point is of little relevance. Second, if debt could be differentiated in terms of its treatment in bankruptcy, then debt-overhang problems would make refinancing in future periods problematic. This situation mimics a very high fixed cost of increasing debt financing and should therefore tend to reinforce our conclusions.

In addition to the external finance premium, we assume that the firm faces a fixed cost, $\mu \geq 0$, when it acquires, but not when it retires, debt:

$$
m\left(D_{t}, D_{t+1}\right)= \begin{cases}0 & \text { if } D_{t+1} \leq D_{t} \\ \mu & \text { if } D_{t+1}>D_{t}\end{cases}
$$

We think of the fixed cost as a simple way of capturing the idea that seeking external finance can exacerbate the conflict of interest between managers and outside financiers, as suggested by Donaldson's (1984) evidence. But there are certainly other sources of fixed costs, such as the sizable one-time fees charged by investment banks for debt or equity offerings (see, for example, Smith 1977, Calomiris and Himmelberg 2002). In the final analysis,

\footnotetext{
${ }^{3}$ A stochastic marginal cost of debt would not, by itself, generate cash holding. As long as the expected cost of external finance exceeds the return to idle liquidity (and the firm faces no other financial frictions), it is strictly preferable for a risk-neutral firm to repay in the current period as much debt as possible and, if need be, refinance tomorrow.
} 
the key ingredient for our results is that additional external finance carries an adjustment cost that cannot be recouped by repayment. ${ }^{4}$ Indeed, this type of asymmetry generates predictions similar to ours in a model in which borrowing incurs a proportional adjustment cost (Kim, Mauer, and Sherman 1998).

At the beginning of each period, the firm inherits the state variables $D_{t}, K_{t}$, and $L_{t}$. The firm services its debt, $r\left(D_{t}\right) D_{t}$, and receives interest on its liquidity, $i L_{t}$. Production and the stochastic shock generate cash flow from operations, $\Pi\left(K_{t}\right)+z_{t}$. These financial and real activities plus the market value of the completely liquid surviving capital stock define the firm's net stock of internal funds (cash), $C_{t} \equiv(1+i) L_{t}-r\left(D_{t}\right) D_{t}+\Pi\left(K_{t}\right)+z_{t}+p(1-\delta) K_{t}$. Finally, at the end of the period the firm chooses next period's stocks of debt and capital, subject to the fixed cost, if applicable.

Outgoing liquidity is a residual, defined as the net stock of internal funds plus debt less the cost of investment,

$$
L_{t+1}=C_{t}+D_{t+1}-D_{t}-p K_{t+1}
$$

In period three, the firm is liquidated and shareholders receive the payoff, $L_{3}$. Otherwise, the firm's payoff in each period is equal to outgoing liquidity, $L_{t+1}$ - the accumulated cash flow from the firm's production, investment, and financing activity — net of the fixed cost, $m\left(D_{t}, D_{t+1}\right)$ :

$$
\begin{aligned}
V\left(D_{t}, K_{t}, L_{t}\right)= & (1+i) L_{t}+\Pi\left(K_{t}\right)+z_{t}-p\left[K_{t+1}-(1-\delta) K_{t}\right] \\
& -\left[1+r\left(D_{t}\right)\right] D_{t}+D_{t+1}-m\left(D_{t}, D_{t+1}\right) .
\end{aligned}
$$

\footnotetext{
${ }^{4} \mathrm{~A}$ constraint on the amount of external funds that the firm can raise would also encourage self-financing. Along these lines, Gross (1995) and Almeida, Campello, and Weisbach (2004) show that firms hoard resources when they face bankruptcy, a state in which they cannot borrow. Quantity constraints of one type or another surely affect some firms, and can, in fact, be seen as the special case of our framework in which the fixed cost is infinitely large. But the widespread availability of distressed financing for risky prospects suggests to us that the more salient financial frictions are captured in prices.
} 
The firm's objective is to maximize the present discounted value of current and expected future payoffs defined by equation (2). Using backward induction to solve this problem gives the following per-period decision problem:

$$
\begin{aligned}
& \max _{\left\{D_{t+1}, K_{t+1}\right\}} V\left(D_{t}, K_{t}, L_{t}\right)+\beta \mathrm{E}_{t} V\left(D_{t+1}, K_{t+1}, L_{t+1}\right) \\
& \text { subject to } L_{t+1} \geq 0 \text { and } D_{t+1} \geq 0 .
\end{aligned}
$$

The first constraint forces investment to be less than or equal to the amount of available resources, which could include new debt. The second constraint forces debt to be nonnegative.

\subsection{Solution Without a Fixed Cost}

To establish a benchmark, we first characterize the optimal financing and investment decisions in the absence of a fixed cost. To conserve on space, we sketch the intuition for our findings and refer the interested reader to our working paper for the complete proofs of the propositions.

Proposition 1: For any given history, $D_{t}, K_{t}$, and $L_{t}$, the financing and investment decisions of the firm can be characterized in terms of two regions of its internal funds, $C_{t}$.

1. When internal funds, $C_{t}$, are sufficiently small, the firm relies on external finance and holds no liquidity $\left(L_{t+1}^{*}=0\right)$. The optimal capital stock and external finance are given jointly by the first constraint in equation (3), which holds with equality, and the following marginal condition: $\Pi^{\prime}\left(K_{t+1}^{*}\right)=p\left[r\left(D_{t+1}^{*}\right)+r^{\prime}\left(D_{t+1}^{*}\right) D_{t+1}^{*}+\delta\right]$.

2. When internal funds, $C_{t}$, are sufficiently large, the firm relies exclusively on internal financing and has no external financial obligations $\left(D_{t+1}^{*}=0\right)$. The optimal capital stock is implicitly defined by $\Pi^{\prime}\left(K_{t+1}^{*}\right)=p(i+\delta)$. Outgoing liquidity, $L_{t+1}^{*}$, is given as a residual by equation (1).

The threshold level of internal funds above which the firm can hold liquidity is strictly increasing in the amount of debt that it carries, $D_{t}$.

Since the marginal cost of debt is greater than the return on internal funds, the firm always uses an additional dollar to retire debt rather than holding it as liquidity. Thus, the 
firm never holds liquidity and debt simultaneously. In fact, liquidity arises as a residual manifestation of good fortune rather than as a deliberate decision. In terms of its financial policy, the firm uses a pecking-order: relatively cheap internal funds are used until they are exhausted and only then is relatively expensive debt tapped. In terms of its investment policy, the firm acquires capital until its marginal revenue product (net of depreciation) is equal to the marginal cost of funds. Since debt is increasingly more expensive than internal funds, the optimal capital stock decreases with the amount of borrowing. Finally, in terms of investment-cash flow sensitivities, investment is unconstrained when the firm has liquidity and no debt. When the firm has debt, investment is financially constrained, displaying excess sensitivity to an extra dollar of cash flow with that dollar divided between investment and paying down debt.

\subsection{Solution With a Fixed Cost}

Financing choices in the baseline model are straightforward because internal funds are just negative external finance with a lower marginal cost (and return). This changes when we introduce a fixed cost of adding debt.

In the third period, the firm makes no decisions because it is exogenously forced into liquidation. There is no limited liability, so the firm's payoff in period three, whether it is positive or negative, is equal to the net stock of cash, $C_{3}$, minus debt, $D_{3}$. In the second period, the firm can get new financing only by incurring the discrete adjustment cost, $\mu>$ 0 . After the firm has incurred the fixed cost in period two, however, there are no future financing decisions. Hence, if the firm acquires additional debt (i.e., if $D_{3}>D_{2}$ ), then the first part of proposition 1 describes its external financing and investment decisions. In particular, additional debt would only be used to buy capital.

Whether the firm refinances in period two is determined by the net benefit from acquiring debt and investing it in physical capital (in which case $D_{3}^{*}, K_{3}^{*}$, and $L_{3}^{*}=0$, where optimal choices are denoted by an asterisk), rather than keeping debt at its current level 
and settling for the capital stock that can be internally financed (in which case $\widetilde{D}_{3}=D_{2}$, $\tilde{K}_{3}=p^{-1} C_{2}$, and $\widetilde{L}_{3}=0$, where financially-constrained choices are denoted by a tilde). This net benefit can be expressed as the difference between the value function evaluated at the optimal choices and the financially-constrained choices:

$$
\begin{aligned}
\mathcal{H}_{2} \equiv V\left(D_{2}, K_{2}, L_{2}\right)+\beta \mathrm{E}_{2}\left[V\left(D_{3}^{*}, K_{3}^{*}, L_{3}^{*}\right)\right] & \\
& -V\left(D_{2}, K_{2}, L_{2}\right)-\beta \mathrm{E}_{2}\left[V\left(\widetilde{D}_{3}, \widetilde{K}_{3}, \widetilde{L}_{3}\right)\right] .
\end{aligned}
$$

Assuming that $C_{2} \geq-p(1-\delta) K_{2}$, which means that the firm has sufficient internal funds to allow it to leave the period with non-negative liquidity (lest the firm have no choice but to refinance), this condition can be expressed as

$$
\begin{aligned}
\mathcal{H}_{2}=\beta\left\{\left[\Pi\left(K_{3}^{*}\right)-\right.\right. & \left.\left.\Pi\left(\tilde{K}_{3}\right)\right]-p\left[K_{3}^{*}-\tilde{K}_{3}\right](i+\delta)\right\}- \\
& -\beta\left\{\left[r\left(D_{3}^{*}\right)-i\right]\left[D_{3}^{*}-D_{2}\right]+\left[r\left(D_{3}^{*}\right)-r\left(D_{2}\right)\right] D_{2}+(1+i) \mu\right\} .
\end{aligned}
$$

The two bracketed expressions capture the real and financial effects, respectively, of additional financing. In the real sector, the firm enjoys revenue from a larger capital stock, but also pays the user cost for this investment. In the financial sector, the increased stock of debt is paid for, the cost of carrying the existing debt increases, and the (compounded) fixed cost is incurred.

In proposition 2, we use the net benefit function $\mathcal{H}_{2}$ to derive a threshold level of internal funds that triggers refinancing.

Proposition 2: For any given history, $D_{2}, K_{2}$, and $L_{2}$, the financing and investment decisions of the firm in period two can be characterized in terms of two regions of its period-two internal funds, $C_{2}$, defined by the threshold $\hat{C}_{2}$.

1. When $C_{2}<\hat{C}_{2}$, the firm increases external finance $\left(D_{3}>D_{2}\right)$ and invests optimally as described in the first part of proposition 1.

2. When $C_{2} \geq \hat{C}_{2}$, the firm does not increase external finance $\left(D_{3}=D_{2}\right)$. If $C_{2}$ is large enough to internally finance the capital stock that is optimal with debt unchanged 
at $D_{2}$, then the firm invests optimally as described in the first and second part of proposition 1. Otherwise, there is under-investment relative to the optimal capital stock described in the first part of proposition 1.

In the first period, the firm's decision problem is complicated by the specter of future costs of additional financing. However, the risk of incurring these costs can be reduced by accumulating resources inside the firm. Such behavior amounts to precautionary saving, which can distort both financial and real decisions.

In period one, the risk of facing the fixed cost in period two can be derived from the optimal financing policy described in proposition 2: the cost will be incurred if and only if $C_{2}<\hat{C}_{2}$. We map this condition into the space of realizations of the revenue shock, calling $\hat{z}_{2}\left(D_{2}, K_{2}\right)$ the critical value of the shock that triggers refinancing. For all realizations of $z_{2}<\hat{z}_{2}\left(D_{2}, K_{2}\right)$, the firm must incur the fixed cost, so the probability of that event is equal to $\int_{-\infty}^{\hat{z}_{2}\left(D_{2}, K_{2}\right)} f\left(z_{2}\right) d z$.

In lemma 1, we derive the marginal effects of the period one decision variables, $D_{2}$ and $K_{2}$, on the expected future cost of additional financing. ${ }^{5}$

Lemma 1: Define $\psi \equiv \Pi^{\prime}\left(\tilde{K}_{3}\right)-\Pi^{\prime}\left(K_{3}^{*}\right)$, where $\tilde{K}_{3}$ and $K_{3}^{*}$ are evaluated at $z_{2}=\hat{z}_{2}$.

$$
\begin{aligned}
& \frac{\partial \mathrm{E}\left[m\left(D_{2}, D_{3}^{*}\right)\right]}{\partial D_{2}}=\mu f\left(\hat{z}_{2}\right)\left[\frac{d \hat{z}_{2}}{d D_{2}}\right]=-\mu f\left(\hat{z}_{2}\right)\left\{(1+i)-\left[r\left(D_{2}\right)+r^{\prime}\left(D_{2}\right) D_{2}\right]-\frac{p r^{\prime}\left(D_{2}\right) D_{2}}{\psi}\right\} \\
& \frac{\partial \mathrm{E}\left[m\left(D_{2}, D_{3}^{*}\right)\right]}{\partial K_{2}}=\mu f\left(\hat{z}_{2}\right)\left[\frac{d \hat{z}_{2}}{d K_{2}}\right]=-\mu f\left(\hat{z}_{2}\right)\left\{\Pi^{\prime}\left(K_{2}\right)-p(1+i)+p(1-\delta)\right\} .
\end{aligned}
$$

An increase in debt in period one, $D_{2}$, has three effects on $\hat{z}_{2}$. First, the additional debt increases the stock of cash in period two by the face value of the added finance plus the return that it earns. This enables the firm to absorb a less favorable shock, thus decreasing the threshold that triggers refinancing. Second, the additional debt must be serviced, although not paid-in-full, which decreases the stock of cash and therefore increases $\hat{z}_{2}$. Finally, the

\footnotetext{
${ }^{5}$ By assumption, the firm's decisions cannot affect the magnitude of the fixed cost, $\mu$, or the probability distribution of the revenue shocks, $f(z)$.
} 
additional debt drives up the marginal cost of funds in period one. Because debt taken on earlier softens the blow from future refinancing costs, investment in period two is more attractive and this leads to a higher $\hat{z}_{2}$.

An increase in the outgoing capital stock, $K_{2}$, has three effects on $\hat{z}_{2}$. First, an additional unit of capital generates revenue of $\Pi^{\prime}\left(K_{2}\right)$ in period two which boosts the stock of cash and decreases $\hat{z}_{2}$. Second, buying capital in period one decreases the stock of cash in period two by $p(1+i)$, which increases $\hat{z}_{2}$. Finally, an additional unit of capital in period one increases the liquidation value of the existing capital stock in period two by $p(1-\delta)$. This means that a larger capital stock can be internally financed, which makes refinancing less urgent and decreases $\hat{z}_{2}$. Combining the latter two effects yields the standard expression for the user cost of internally-financed capital, $p(i+\delta)$.

The heart of the firm's decision problem in period one is the trade-off between direct effects in the current period and expected future financing costs. This comparison is captured by $\phi=\frac{\mu f\left(\hat{z}_{2}\right)}{1+\mu f\left(\hat{z}_{2}\right)}$, which measures the relative importance of the future refinancing cost in the firm's objective function. The parameter $\phi$ lies between 0 and 1 and is strictly increasing in $\mu$ and in $f\left(\hat{z}_{2}\right)$.

Proposition 3 and its corollary summarize the firm's unconstrained policy in period one. We can close the model like we did in proposition 2 by defining the net benefit from refinancing in period one - a function analogous to $\mathcal{H}_{2}$ - and then show that there is a unique threshold of internal funds that triggers refinancing.

Proposition 3: Suppose that the fixed cost in period one is irrelevant either because it is sunk or because it was not incurred. Then, for any given history, $D_{1}, K_{1}$, and $L_{1}$, financing and investment decisions of the firm in period one can be characterized in terms of two regions of its period-one internal funds, $C_{1}$, defined by the threshold $\bar{C}_{1}$.

1. When $C_{1} \leq \bar{C}_{1}$, the firm relies on external finance and holds no liquidity. The optimal capital stock and debt are given jointly by the first constraint in equation (3), which holds with equality, and the following marginal condition:

$$
\Pi^{\prime}\left(K_{2}^{*}\right)=p\left\{r\left(D_{2}^{*}\right)+r^{\prime}\left(D_{2}^{*}\right) D_{2}^{*}+\delta-\phi\left[1-\frac{p r^{\prime}\left(D_{2}^{*}\right) D_{2}^{*}}{\psi}\right]\right\} .
$$


2. When $C_{1}>\bar{C}_{1}$, the firm holds both liquidity and external finance. The optimal capital stock and debt are given jointly by the following two marginal conditions:

$$
\Pi^{\prime}\left(K_{2}^{*}\right)=p(i+\delta) \text { and } r\left(D_{2}^{*}\right)+r^{\prime}\left(D_{2}^{*}\right) D_{2}^{*}-\phi\left[1-\frac{p r^{\prime}\left(D_{2}^{*}\right) D_{2}^{*}}{\psi}\right]=i \text {. }
$$

Outgoing liquidity is given as a residual by equation (1).

Corollary 1: $\bar{C}_{1}$ is given by the first constraint in equation (3) when it holds with equality. $\bar{C}_{1}$ is strictly decreasing in $\phi$ and approaches infinity as $\phi$ approaches zero. When $C_{1} \leq \bar{C}_{1}$, the firm divides an additional dollar between capital investment and retirement of debt. When $C_{1}>\bar{C}_{1}$, neither investment nor financing is responsive to additional cash flow because it is channeled in its entirety into idle liquidity.

The key feature of the model is that the fixed cost modifies the marginal cost of debt by $\phi\left[1-\frac{p r^{\prime}\left(D_{2}\right) D_{2}}{\psi}\right]$. Two forces are at work inside the brackets of this term: a dollar that is not used to repay debt can be used in the future to stave off refinancing costs; however, not repaying debt drives up its marginal cost in the current period. On balance, the benefit of retaining the dollar dominates, so that the marginal cost of debt falls by an amount that is scaled by the relative importance of the refinancing costs, $\phi$. Given the added benefit from debt, internal finance is not always less expensive than external finance; instead, internal finance is more expensive for low levels of debt. As a consequence, the firms holds liquidity and debt simultaneously when $C_{1}>\bar{C}_{1}$. This modification also upsets the usual peckingorder of funds: the firm uses debt until its marginal cost is equal to the marginal cost of internal finance, $i$, then relies on internal finance until it is exhausted and, finally, borrows more.

The added benefit of debt affects the firm's investment policy, too. When productive capital is externally financed $\left(C_{1} \leq \bar{C}_{1}\right)$, the fixed cost reduces the user cost of capital and raises the optimal capital stock compared with the benchmark solution in the first part of proposition 1. Thus, the fixed-cost financial friction partly offsets the negative effect that the external finance financial friction has on the optimal capital stock. When productive 
capital is internally financed $\left(C_{1}>\bar{C}_{1}\right)$, the optimal capital stock remains the same as in the benchmark case in the second part of proposition 1 because the trade-off between capital and liquidity is unaffected by the introduction of the fixed cost.

The empirical predictions of our model line up nicely with the stylized facts about corporate cash holding and investment (see, for example, Almeida, Campello, and Weisbach 2004, Kim, Mauer, and Sherman 1998, Opler, Pinkowitz, Stulz, and Williamson 1999). In the cross-sectional dimension, liquid assets tend to be held by firms with strong growth opportunities, as captured by a high market-to-book ratio. Likewise in our model, firms with relatively strong investment opportunities have a larger distortion term (because $\psi$ is bigger) and, therefore, are apt to hold idle cash. ${ }^{6}$ Intuitively, growth firms hold more cash because it is especially costly for them to have their future investment hampered by a short-fall in financial resources. In the time-series dimension, studies have found that firms with cash holdings continue to accumulate cash flow. Likewise in our model, firms with idle cash add to their stockpile because it provides a buffer against adverse shocks that may occur. Lastly, a fixed-cost financial friction makes the relationship between investment and cash flow a misleading indicator of financial frictions. In particular, investment (as well as debt) is completely unresponsive to cash flow when $C_{1}>\bar{C}_{1}$; instead, the firm channels all of an additional dollar into liquidity, a result that may help explain the fragility of reduced-form estimates of investment-cash flow sensitivities. Our results also suggest that researchers should use caution when screening for liquidity constraints using firm characteristics. For example, one might think that a cash-rich firm would not face financial constraints; but in our model a large stock of cash may indicate that the firm anticipates facing financing constraints in the future.

\footnotetext{
${ }^{6} \mathrm{~A}$ change in investment opportunities can be modeled by multiplying the production function by a scaling parameter: $\alpha \Pi(K)$. An increase in $\alpha$ widens the difference between the marginal revenue products of any two levels of capital; it also increases the optimal capital stock. Both of these effects increase $\psi$ and, therefore, the distortion term.
} 


\section{Appendix}

The appendix contains the proofs of the propositions.

Proof of Proposition 1: When there is no fixed-cost financial friction $(\mu=0)$ the maximization problem and the two constraints in (3) yield the following first-order conditions:

$$
\begin{gathered}
-p+\beta\left[\Pi^{\prime}\left(K_{t+1}^{*}\right)+p(1-\delta)\right]-\lambda_{1}=0 \\
1-\beta\left[1+r\left(D_{t+1}^{*}\right)+r^{\prime}\left(D_{t+1}^{*}\right) D_{t+1}^{*}\right]+\lambda_{1} p^{-1}+\lambda_{2}=0 .
\end{gathered}
$$

When $D_{t+1}>0, \lambda_{2}=0$. In this case, we can solve for $\lambda_{1}$ using the first-order condition for debt (equation (5)):

$$
\begin{aligned}
\lambda_{1} & =p \beta\left[1+r\left(D_{t+1}^{*}\right)+r^{\prime}\left(D_{t+1}^{*}\right) D_{t+1}^{*}-(1+i)\right] \\
& =p \beta\left[r\left(D_{t+1}^{*}\right)+r^{\prime}\left(D_{t+1}^{*}\right) D_{t+1}^{*}-i\right]>0 .
\end{aligned}
$$

Since $\lambda_{1}>0$, the first constraint in equation (3) holds with equality, which means that the firm holds no liquidity. $K_{t+1}^{*}$ and $D_{t+1}^{*}$ are determined jointly by the first constraint and the following marginal optimality condition, which is derived by substituting the solution for $\lambda_{1}$ (equation (6)) into equation (4):

$$
\begin{gathered}
-p+\beta\left[\Pi^{\prime}\left(K_{t+1}^{*}\right)+p(1-\delta)\right]=p \beta\left[r\left(D_{t+1}^{*}\right)+r^{\prime}\left(D_{t+1}^{*}\right) D_{t+1}^{*}-i\right] \Leftrightarrow \\
\Pi^{\prime}\left(K_{t+1}^{*}\right)=p\left[r\left(D_{t+1}^{*}\right)+r^{\prime}\left(D_{t+1}^{*}\right) D_{t+1}^{*}+\delta\right] .
\end{gathered}
$$

When $D_{t+1}=0, r\left(D_{t+1}\right)=i$ and $r^{\prime}\left(D_{t+1}\right) D_{t+1}=0$. In this case, we can solve for $\lambda_{1}$ and $\lambda_{2}$ using the first-order condition for debt (equation (5)):

$$
\begin{aligned}
\lambda_{1} p^{-1}+\lambda_{2} & =p \beta\left[1+r\left(D_{t+1}^{*}\right)+r^{\prime}\left(D_{t+1}^{*}\right) D_{t+1}^{*}-(1+i)\right] \\
& =p \beta[(1+i)-(1+i)]=0 .
\end{aligned}
$$


The multipliers must be non-negative so $\lambda_{1}=\lambda_{2}=0$. Since $\lambda_{1}=0$, we can solve for the optimal capital stock using equation (4):

$$
\begin{gathered}
-p+\beta\left[\Pi^{\prime}\left(K_{t+1}^{*}\right)+p(1-\delta)\right]=0 \Leftrightarrow \\
\Pi^{\prime}\left(K_{t+1}^{*}\right)=p(i+\delta) .
\end{gathered}
$$

The firm's liquidity holding is determined as a residual using the first constraint in equation (3).

Finally, the firm is better off when it holds liquidity and no debt than the other way around. This follows from the fact that in the former case $L_{t+1}^{*}$ and $K_{t+1}^{*}$ are larger and $D_{t+1}^{*}$ is smaller, and from $V(\cdot)$ being strictly increasing in $L_{t}$ and $K_{t}$ and strictly decreasing in $D_{t}$.

Proof of Proposition 2: Notice that the firm has a non-trivial refinancing decision to make only if it has enough internal funds to leave the period with non-negative liquidity. Otherwise, it is exogenously forced to refinance in order to escape financial distress, i.e., the first constraint in the maximization problem (3) is violated if $\widetilde{K}_{3}<0$ and $D_{3}=D_{2}$. Therefore, we can restrict ourselves to the case of $C_{2} \geq-p(1-\delta) K_{2}$. Using the fact that all newly acquired funds are invested in physical capital, i.e., that $D_{3}^{*}-D_{2}=p\left[K_{3}^{*}-\widetilde{K}_{3}\right]$, the net benefit can be rewritten as

$$
\begin{aligned}
\mathcal{H}_{2}=\beta\left\{\left[\Pi\left(K_{3}^{*}\right)-\Pi\left(\tilde{K}_{3}\right)\right]-p\left[K_{3}^{*}-\tilde{K}_{3}\right][\right. & \left.\left.r\left(D_{2}\right)+\delta\right]\right\} \\
& -\beta\left\{\left[r\left(D_{3}^{*}\right)-r\left(D_{2}\right)\right] D_{3}^{*}+(1+i) \mu\right\} .
\end{aligned}
$$


Differentiation with respect to $C_{2}$ yields.

$$
\begin{aligned}
\frac{\partial \mathcal{H}_{2}}{\partial C_{2}}= & \beta\left\{\Pi^{\prime}\left(K_{3}^{*}\right) \frac{\partial K_{3}^{*}}{\partial C_{2}}-\Pi^{\prime}\left(\tilde{K}_{3}\right) \frac{\partial \tilde{K}_{3}}{\partial C_{2}}-p\left[\frac{\partial K_{3}^{*}}{\partial C_{2}}-\frac{\partial \tilde{K}_{3}}{\partial C_{2}}\right]\left[r\left(D_{2}\right)+\delta\right]\right. \\
& \left.-\left[r\left(D_{3}^{*}\right)-r\left(D_{2}\right)\right] \frac{\partial D_{3}^{*}}{\partial C_{2}}-r^{\prime}\left(D_{3}^{*}\right) D_{3}^{*} \frac{\partial D_{3}^{*}}{\partial C_{2}}\right\} \\
= & \beta\left\{\left\{\Pi^{\prime}\left(K_{3}^{*}\right)-p\left[r\left(D_{2}\right)+\delta\right]\right\} \frac{\partial K_{3}^{*}}{\partial C_{2}}-\left\{\Pi^{\prime}\left(\tilde{K}_{3}\right)-p\left[r\left(D_{2}\right)+\delta\right]\right\} \frac{\partial \tilde{K}_{3}}{\partial C_{2}}\right. \\
& \left.-\left[r\left(D_{3}^{*}\right)+r^{\prime}\left(D_{3}^{*}\right) D_{3}^{*}-r\left(D_{2}\right)\right] \frac{\partial D_{3}^{*}}{\partial C_{2}}\right\} \\
= & \beta\left\{\left\{\Pi^{\prime}\left(K_{3}^{*}\right)-p\left[r\left(D_{2}\right)+\delta\right]\right\} \frac{\partial K_{3}^{*}}{\partial C_{2}}-\left\{\Pi^{\prime}\left(\tilde{K}_{3}\right)-p\left[r\left(D_{2}\right)+\delta\right]\right\} \frac{\partial \tilde{K}_{3}}{\partial C_{2}}\right. \\
= & \beta\left\{\left\{\Pi^{\prime}\left(K_{3}^{*}\right)-p\left[r\left(D_{3}^{*}\right)+r^{\prime}\left(D_{3}^{*}\right) D_{3}^{*}+\delta\right]\right\} \frac{\partial K_{3}^{*}}{\partial C_{2}}\right. \\
& \left.-p^{-1}\left\{\Pi^{\prime}\left(\tilde{K}_{3}\right)-p\left[r\left(D_{3}^{*}\right)+r_{3}^{*}\left(D_{3}^{*}\right) D_{3}^{*}+\delta\right]\right\}\right\} \\
= & -\beta p^{-1}\left\{\Pi^{\prime}\left(\tilde{K}_{3}\right)-p\left[r\left(D_{3}^{*}\right)+r^{\prime}\left(D_{3}^{*}\right) D_{3}^{*}+\delta\right]\right\} \\
& -\beta p^{-1}\left[\Pi^{\prime}\left(\tilde{K}_{3}\right)-\Pi^{\prime}\left(K_{3}^{*}\right)\right]<0 . \\
&
\end{aligned}
$$

Notice that as $\tilde{K}_{3}$ approaches zero, $\Pi^{\prime}\left(\tilde{K}_{3}\right)$ approaches infinity and $\frac{\partial \mathcal{H}_{2}}{\partial C_{2}}$ approaches negative infinity. This implies that as $C_{2}$ approaches its lower bound of $-p(1-\delta) K_{2}, \mathcal{H}_{2}\left(C_{2}\right)$ approaches infinity. Moreover, for a sufficiently large $C_{2}, \tilde{K}_{3}=K_{3}^{*}$ and $D_{3}^{*}=D_{2}$, which implies that $\mathcal{H}_{2}\left(C_{2}\right)=-\mu<0$. It now follows from the Intermediate Value Theorem that there exists a unique $\hat{C}_{2}$ such that $\mathcal{H}_{2}\left(\hat{C}_{2}\right)=0$.

There are two cases to consider:

1. $C_{2}<\hat{C}_{2}$. In this case, the firm refinances. The fixed cost of refinancing is sunk so the first part of proposition 1 describes the optimal behavior when $D_{3}^{*}>0$. 
2. $C_{2} \geq \hat{C}_{2}$. In this case, the optimal behavior depends on the realization of $C_{2}$. If $C_{2}$ is insufficient to finance the capital stock that is optimal when debt is equal to $D_{2}$, then the firm invests as much as possible, holds no liquidity, and leaves debt at $D_{2}$. Otherwise, as $C_{2}$ increases, the optimal behavior is described initially by the first and subsequently by the second part of proposition 1 .

Proof of Lemma 1: Since both $\mu$ and the density function are independent of the decision variables in period one, Leibnitz's rule implies that $\frac{\partial \mathrm{E}\left[m\left(D_{2}, D_{3}^{*}\right)\right]}{\partial D_{2}}=\mu f\left(\hat{z}_{2}\right)\left[\frac{\mathrm{d} \hat{z}_{2}}{\mathrm{~d} D_{2}}\right]$. The same argument applies to the derivative with respect to $K_{2}$.

Next, recall the derivation of $\frac{\partial \mathcal{H}_{2}}{\partial C_{2}}$ and that because all new financing is used to buy capital, $D_{3}^{*}-D_{2}=p\left[K_{3}^{*}-\tilde{K}_{3}\right]$. Differentiate $\mathcal{H}_{2}$ with respect to $z_{2}, K_{2}$, and $D_{2}$.

$$
\begin{aligned}
\frac{\mathrm{d} \mathcal{H}_{2}}{\mathrm{~d} z_{2}}= & \frac{\partial \mathcal{H}_{2}}{\partial C_{2}} \frac{\partial C_{2}}{\partial z_{2}}=\frac{\partial \mathcal{H}_{2}}{\partial C_{2}}=-\beta p^{-1}\left[\Pi^{\prime}\left(\tilde{K}_{3}\right)-\Pi^{\prime}\left(K_{3}^{*}\right)\right]=-\beta p^{-1} \psi \\
\frac{\mathrm{d} \mathcal{H}_{2}}{\mathrm{~d} D_{2}}= & \beta\left\{\Pi^{\prime}\left(K_{3}^{*}\right) \frac{\partial K_{3}^{*}}{\partial C_{2}} \frac{\partial C_{2}}{\partial D_{2}}-\Pi^{\prime}\left(\tilde{K}_{3}\right) \frac{\partial \tilde{K}_{3}}{\partial C_{2}} \frac{\partial C_{2}}{\partial D_{2}}-p\left[\frac{\partial K_{3}^{*}}{\partial C_{2}} \frac{\partial C_{2}}{\partial D_{2}}-\frac{\partial \tilde{K}_{3}}{\partial C_{2}} \frac{\partial C_{2}}{\partial D_{2}}\right]\left[r\left(D_{2}\right)+\delta\right]\right. \\
& -p\left[K_{3}^{*}-\tilde{K}_{3}\right] r^{\prime}\left(D_{2}\right)-\left[r\left(D_{3}^{*}\right)-r\left(D_{2}\right)\right] \frac{\partial D_{3}^{*}}{\partial C_{2}} \frac{\partial C_{2}}{\partial D_{2}} \\
& \left.-r^{\prime}\left(D_{3}^{*}\right) D_{3}^{*} \frac{\partial D_{3}^{*}}{\partial C_{2}} \frac{\partial C_{2}}{\partial D_{2}}+r^{\prime}\left(D_{2}\right) D_{3}^{*}\right\} \\
= & \beta\left\{\Pi^{\prime}\left(K_{3}^{*}\right) \frac{\partial K_{3}^{*}}{\partial C_{2}}-\Pi^{\prime}\left(\tilde{K}_{3}\right) \frac{\partial \tilde{K}_{3}}{\partial C_{2}}-p\left[\frac{\partial K_{3}^{*}}{\partial C_{2}}-\frac{\partial \tilde{K}_{3}}{\partial C_{2}}\right]\left[r\left(D_{2}\right)+\delta\right]\right. \\
& \left.-\left[r\left(D_{3}^{*}\right)-r\left(D_{2}\right)\right] \frac{\partial D_{3}^{*}}{\partial C_{2}}-r^{\prime}\left(D_{3}^{*}\right) D_{3}^{*} \frac{\partial D_{3}^{*}}{\partial C_{2}}\right\} \frac{\partial C_{2}}{\partial D_{2}} \\
& +\beta r^{\prime}\left(D_{2}\right)\left\{D_{3}^{*}-p\left[K_{3}^{*}-\tilde{K}_{3}\right]\right\} \\
= & \frac{\partial \mathcal{H}_{2}}{\partial C_{2}} \frac{\partial C_{2}}{\partial D_{2}}+\beta r^{\prime}\left(D_{2}\right) D_{2} .
\end{aligned}
$$




$$
\begin{aligned}
\frac{\mathrm{d} \mathcal{H}_{2}}{\mathrm{~d} K_{2}}= & \beta\left\{\Pi^{\prime}\left(K_{3}^{*}\right) \frac{\partial K_{3}^{*}}{\partial C_{2}} \frac{\partial C_{2}}{\partial K_{2}}-\Pi^{\prime}\left(\tilde{K}_{3}\right)\left[\frac{\partial \tilde{K}_{3}}{\partial C_{2}} \frac{\partial C_{2}}{\partial K_{2}}\right]-\left[r\left(D_{3}^{*}\right)-r\left(D_{2}\right)\right] \frac{\partial D_{3}^{*}}{\partial C_{2}} \frac{\partial C_{2}}{\partial K_{2}}\right. \\
= & \left.-p\left\{\frac{\partial K_{3}^{*}}{\partial C_{2}} \frac{\partial C_{2}}{\partial K_{2}}-\left[\frac{\partial \tilde{K}_{3}}{\partial C_{2}} \frac{\partial C_{2}}{\partial K_{2}}\right]\right\}\left[r\left(D_{2}\right)+\delta\right]-r^{\prime}\left(D_{3}^{*}\right) D_{3}^{*} \frac{\partial D_{3}^{*}}{\partial C_{2}} \frac{\partial C_{2}}{\partial K_{2}}\right\} \\
= & \beta\left\{\Pi^{\prime}\left(K_{3}^{*}\right) \frac{\partial K_{3}^{*}}{\partial C_{2}}-\Pi^{\prime}\left(\tilde{K}_{3}\right)\left[\frac{\partial \tilde{K}_{3}}{\partial C_{2}}\right]-\left[r\left(D_{3}^{*}\right)-r\left(D_{2}\right)\right] \frac{\partial D_{3}^{*}}{\partial C_{2}}\right. \\
& \left.-p\left\{\frac{\partial K_{3}^{*}}{\partial C_{2}}-\left[\frac{\partial \tilde{K}_{3}}{\partial C_{2}}\right]\right\}\left[r\left(D_{2}\right)+\delta\right]-r^{\prime}\left(D_{3}^{*}\right) D_{3}^{*} \frac{\partial D_{3}^{*}}{\partial C_{2}}\right\} \frac{\partial C_{2}}{\partial K_{2}} \\
= & \frac{\partial \mathcal{H}_{2}}{\partial C_{2}} \frac{\partial C_{2}}{\partial K_{2}}=\frac{\partial \mathcal{H}_{2}}{\partial C_{2}}\left[\Pi^{\prime}\left(K_{2}\right)-p(1+i)+p(1-\delta)\right] \\
= & \frac{\partial \mathcal{H}_{2}}{\partial C_{2}}\left[\Pi^{\prime}\left(K_{2}\right)-p(i+\delta)\right] .
\end{aligned}
$$

We use the Implicit Function Theorem to complete the proof:

$$
\begin{aligned}
& \frac{\mathrm{d} \hat{z}_{2}}{\mathrm{~d} D_{2}}=-\left.\frac{\frac{\mathrm{d} \mathcal{H}_{2}}{\mathrm{~d} D_{2}}}{\frac{\mathrm{d} \mathcal{H}_{2}}{\mathrm{~d} z_{2}}}\right|_{z_{2}=\hat{z}_{2}}=-\frac{\frac{\partial \mathcal{H}_{2}}{\partial C_{2}}\left\{(1+i)-\left[r\left(D_{2}\right)+r^{\prime}\left(D_{2}\right) D_{2}\right]\right\}+\beta r^{\prime}\left(D_{2}\right) D_{2}}{\frac{\partial \mathcal{H}_{2}}{\partial C_{2}}} \\
&=-\left\{(1+i)-\left[r\left(D_{2}\right)+r^{\prime}\left(D_{2}\right) D_{2}\right]\right\}-\frac{\beta r^{\prime}\left(D_{2}\right) D_{2}}{-\beta p^{-1}\left[\Pi^{\prime}\left(\tilde{K}_{3}\right)-\Pi^{\prime}\left(K_{3}^{*}\right)\right]} \\
&=-\left\{(1+i)-\left[r\left(D_{2}\right)+r^{\prime}\left(D_{2}\right) D_{2}\right]-\frac{p r^{\prime}\left(D_{2}\right) D_{2}}{\psi}\right\} . \\
& \frac{\mathrm{d} \hat{z}_{2}}{\mathrm{~d} K_{2}}=-\left.\frac{\mathrm{d} \mathcal{H}_{2}}{\frac{\mathrm{d} \mathcal{H}_{2}}{\mathrm{~d} z_{2}}}\right|_{z_{2}=\hat{z}_{2}}=-\frac{\frac{\partial \mathcal{H}_{2}}{\partial C_{2}}\left\{\Pi^{\prime}\left(K_{2}\right)-p(i+\delta)\right\}}{\frac{\partial \mathcal{H}_{2}}{\partial C_{2}}} \\
&=-\left\{\Pi^{\prime}\left(K_{2}\right)-p(i+\delta)\right\}
\end{aligned}
$$


Proof of Proposition 3: When there is a fixed-cost financial friction $(\mu=0)$, the maximization problem and the two constraints in (3) yield the following first-order conditions:

$$
\begin{gathered}
-p+\beta\left\{\Pi^{\prime}\left(K_{2}^{*}\right)+p(1-\delta)-\frac{\partial \mathrm{E}\left[m\left(D_{2}^{*}, D_{3}^{*}\right)\right]}{\partial K_{2}^{*}}\right\}-\lambda_{1}=0 \\
1-\beta\left\{1+r\left(D_{2}^{*}\right)+r^{\prime}\left(D_{2}^{*}\right) D_{2}^{*}+\frac{\partial \mathrm{E}\left[m\left(D_{2}^{*}, D_{3}^{*}\right)\right]}{\partial D_{2}^{*}}\right\}+\lambda_{1} p^{-1}+\lambda_{2}=0 .
\end{gathered}
$$

There are three cases to consider.

When $D_{2}=0, \lambda_{1} \geq 0$ and $\lambda_{2} \geq 0$. In this case, we can solve for $\lambda_{1}$ and $\lambda_{2}$ using the first-order condition for debt (equation (8)):

$$
\begin{aligned}
p^{-1} \lambda_{1}+\lambda_{2} & =\beta\left\{r\left(D_{2}^{*}\right)+r^{\prime}\left(D_{2}^{*}\right) D_{2}^{*}-i+\frac{\partial \mathrm{E}\left[m\left(D_{2}^{*}, D_{3}^{*}\right)\right]}{\partial D_{2}^{*}}\right\} \\
& =\beta \frac{\partial \mathrm{E}\left[m\left(D_{2}^{*}, D_{3}^{*}\right)\right]}{\partial D_{2}^{*}} \\
& =-\beta \mu f\left(\hat{z}_{2}\right)<0 .
\end{aligned}
$$

This is a contradiction, which rules out the possibility that the optimal stock of debt is equal to zero.

When $L_{2}>0$ and $D_{2}>0, \lambda_{1}=0$ and $\lambda_{2}=0$. The optimal capital stock and debt are given jointly by the two first-order conditions. Start with the first-order condition with respect to capital (equation (7)):

$$
\begin{aligned}
& \beta\left\{\Pi^{\prime}\left(K_{2}^{*}\right)-p(i+\delta)-\frac{\partial \mathrm{E}\left[m\left(D_{2}^{*}, D_{3}^{*}\right)\right]}{\partial K_{2}^{*}}\right\}=0 \Leftrightarrow 0 \\
& \Pi^{\prime}\left(K_{2}^{*}\right)=p(i+\delta)-\mu f\left(\hat{z}_{2}\right)\left\{\Pi^{\prime}\left(K_{2}^{*}\right)-p(i+\delta)\right\} \Leftrightarrow \\
& \Pi^{\prime}\left(K_{2}^{*}\right)=p(i+\delta)
\end{aligned}
$$


Next, consider the first order condition with respect to debt (equation (8)):

$$
\begin{gathered}
r\left(D_{2}^{*}\right)+r^{\prime}\left(D_{2}^{*}\right) D_{2}^{*}-i+\frac{\partial \mathrm{E}\left[m\left(D_{2}^{*}, D_{3}^{*}\right)\right]}{\partial D_{2}^{*}}=0 \\
r\left(D_{2}^{*}\right)+r^{\prime}\left(D_{2}^{*}\right) D_{2}^{*}-i-\mu f\left(\hat{z}_{2}\right)\left\{(1+i)-\left[r\left(D_{2}^{*}\right)+r^{\prime}\left(D_{2}^{*}\right) D_{2}^{*}\right]-\frac{p r^{\prime}\left(D_{2}^{*}\right) D_{2}^{*}}{\psi}\right\}=0 \\
r\left(D_{2}^{*}\right)+r^{\prime}\left(D_{2}^{*}\right) D_{2}^{*}-\phi\left[1-\frac{p r^{\prime}\left(D_{2}^{*}\right) D_{2}^{*}}{\psi}\right]=i .
\end{gathered}
$$

The firm's liquidity holding is determined as a residual using the first constraint in equation (3).

When $L_{2}=0$ and $D_{2}>0, \lambda_{1} \geq 0$ and $\lambda_{2}=0 . K_{2}^{*}$ and $D_{2}^{*}$ are determined jointly by the first constraint in equation (3) and the following marginal optimality condition, which is derived by substituting the solution for $\lambda_{1}$ (equation (8)) into equation (7):

$$
\begin{aligned}
\beta\left\{\Pi^{\prime}\left(K_{2}^{*}\right)-p(i+\delta)-\frac{\partial \mathrm{E}\left[m\left(D_{2}^{*}, D_{3}^{*}\right)\right]}{\left.\partial K_{2}^{*}\right\}}\right. & -p \beta\left\{r\left(D_{2}^{*}\right)+r^{\prime}\left(D_{2}^{*}\right) D_{2}^{*}-i+\frac{\partial \mathrm{E}\left[m\left(D_{2}^{*}, D_{3}^{*}\right)\right]}{\partial D_{2}^{*}}\right\}=0 \\
\Pi^{\prime}\left(K_{2}^{*}\right)= & p\left[r\left(D_{2}^{*}\right)+r^{\prime}\left(D_{2}^{*}\right) D_{2}^{*}+\delta\right]+p \frac{\partial \mathrm{E}\left[m\left(D_{2}^{*}, D_{3}^{*}\right)\right]}{\partial D_{2}^{*}}+\frac{\partial \mathrm{E}\left[m\left(D_{2}^{*}, D_{3}^{*}\right)\right]}{\partial K_{2}^{*}} \\
\Pi^{\prime}\left(K_{2}^{*}\right)= & p\left[r\left(D_{2}^{*}\right)+r^{\prime}\left(D_{2}^{*}\right) D_{2}^{*}+\delta\right]-p \mu f\left(\hat{z}_{2}\right)\left\{(1+i)-\left[r\left(D_{2}^{*}\right)+r^{\prime}\left(D_{2}^{*}\right) D_{2}^{*}\right]\right. \\
& \left.-\frac{p r^{\prime}\left(D_{2}^{*}\right) D_{2}^{*}}{\psi}+\Pi^{\prime}\left(K_{2}^{*}\right) p^{-1}-(i+\delta)\right\} \\
\Pi^{\prime}\left(K_{2}^{*}\right)= & p\left[r\left(D_{2}^{*}\right)+r^{\prime}\left(D_{2}^{*}\right) D_{2}^{*}+\delta\right]-p \phi\left[1-\frac{p r^{\prime}\left(D_{2}^{*}\right) D_{2}^{*}}{\psi}\right] .
\end{aligned}
$$


Proof of Corollary 1: (1) $\bar{C}_{1}$ is implicitly defined by the following equation:

$$
\mathcal{G}_{1}=r\left(D_{2}^{*}\left(\bar{C}_{1}\right)\right)+r^{\prime}\left(D_{2}^{*}\left(\bar{C}_{1}\right)\right) D_{2}^{*}\left(\bar{C}_{1}\right)+\phi\left[\frac{p r^{\prime}\left(D_{2}^{*}\left(\bar{C}_{1}\right)\right) D_{2}^{*}\left(\bar{C}_{1}\right)}{\psi}\right]-(i+\phi)=0
$$

Differentiate $\mathcal{G}_{1}$ with respect to $C_{1}$ and with respect to $\phi$ :

$$
\begin{aligned}
\frac{\mathrm{d} \mathcal{G}_{1}}{\mathrm{~d} C_{1}} & =2 r^{\prime}\left(D_{2}^{*}\right) \frac{\partial D_{2}^{*}}{\partial C_{1}}+r^{\prime \prime}\left(D_{2}^{*}\right) D_{2}^{*} \frac{\partial D_{2}^{*}}{\partial C_{1}}+p\left(\frac{\phi}{\psi}\right)\left\{r^{\prime}\left(D_{2}^{*}\right) \frac{\partial D_{2}^{*}}{\partial C_{1}}+r^{\prime \prime}\left(D_{2}^{*}\right) D_{2}^{*} \frac{\partial D_{2}^{*}}{\partial C_{1}}\right\} \\
& =\left\{r^{\prime}\left(D_{2}^{*}\right)+\left[1+p\left(\frac{\phi}{\psi}\right)\right]\left[r^{\prime}\left(D_{2}^{*}\right)+r^{\prime \prime}\left(D_{2}^{*}\right) D_{2}^{*}\right]\right\} \frac{\partial D_{2}^{*}}{\partial C_{1}}<0 . \\
\frac{\mathrm{d} \mathcal{G}_{1}}{\mathrm{~d} \phi} & =\frac{p r^{\prime}\left(D_{2}^{*}\right) D_{2}^{*}}{\psi}-1 .
\end{aligned}
$$

We use the Implicit Function Theorem to complete the proof:

$$
\frac{\mathrm{d} \bar{C}_{1}}{\mathrm{~d} \phi}=-\left.\frac{\frac{\mathrm{d} \mathcal{G}_{1}}{\mathrm{~d} \phi}}{\frac{\mathrm{d} \mathcal{G}_{1}}{\mathrm{~d} C_{1}}}\right|_{C_{1}=\bar{C}_{1}}=\frac{\partial \mathcal{G}_{1}}{\partial \phi}\left[-\left(\frac{\partial \mathcal{G}_{1}}{\partial C_{1}}\right)^{-1}\right]
$$

This derivative takes the same sign as $\frac{\partial \mathcal{G}_{1}}{\partial \phi}$ which is negative at $\bar{C}_{1}$ :

$$
\begin{gathered}
p(i+\delta)=\Pi^{\prime}\left(K_{1}^{*}\left(\bar{C}_{1}\right)\right)=p\left[r\left(D_{2}^{*}\right)+r^{\prime}\left(D_{2}^{*}\right) D_{2}^{*}+\delta\right]-p \phi\left[1-\frac{\left.p r^{\prime}\left(D_{2}^{*}\right) D_{2}^{*}\right]}{\psi}\right] \Leftrightarrow \\
\phi\left[1-\frac{\left.p r^{\prime}\left(D_{2}^{*}\right) D_{2}^{*}\right]}{\psi}\right]=r\left(D_{2}^{*}\right)+r^{\prime}\left(D_{2}^{*}\right) D_{2}^{*}-i>0 \Rightarrow \\
\frac{p r^{\prime}\left(D_{2}^{*}\right) D_{2}^{*}}{\psi}-1<0 .
\end{gathered}
$$

(2) This statement follows directly from the proof of proposition 3.

(3) This statement follows from the fact that optimal solutions for debt and capital are independent of $C_{1}$ when $C_{1}>\bar{C}_{1}$.

Closing the model: To close the model, define the net benefit of refinancing in period one as the difference in payoff between the unconstrained decision described in proposition 3 (denoted by an asterisk) and the decision constrained by the availability of internal funds 
(denoted by a tilde):

$$
\begin{aligned}
\mathcal{H}_{1}=\beta\left\{\left\{\Pi\left(K_{2}^{*}\right)-\Pi\left(\tilde{K}_{2}\right)\right\}-p\left[K_{2}^{*}-\tilde{K}_{2}\right](i+\delta)\right\} \\
-\beta\left\{\left[r\left(D_{2}^{*}\right)-i\right]\left[D_{2}^{*}-D_{1}\right]+\left[r\left(D_{2}^{*}\right)-r\left(D_{1}\right)\right] D_{1}+(1+i) \mu-\mu \int_{\hat{z}_{2}\left(D_{2}^{*}, K_{2}^{*}\right)}^{\hat{z}_{2}\left(D_{1}, \tilde{K}_{2}\right)} f(z) d z\right\} .
\end{aligned}
$$

Again, keep in mind that because the firm is forced to avoid financial distress, refraining from taking on more debt is an option only if $\tilde{K}_{2} \geq 0$, so the domain of the $\mathcal{H}_{1}$ is restricted to $C_{1} \geq-p(1-\delta) K_{1}$. Also, recall that all new financing must be used to buy capital, making $D_{2}^{*}-D_{1}=p\left[K_{2}^{*}-\tilde{K}_{2}\right]$.

Differentiate $\mathcal{H}_{1}$ with respect to $C_{1}$ :

$$
\begin{aligned}
& \frac{\partial \mathcal{H}_{1}}{\partial C_{1}}=\beta\left\{\Pi^{\prime}\left(K_{2}^{*}\right) \frac{\partial K_{2}^{*}}{\partial C_{1}}-\Pi^{\prime}\left(\tilde{K}_{2}\right) \frac{\partial \tilde{K}_{2}}{\partial C_{1}}-p\left[\frac{\partial K_{2}^{*}}{\partial C_{1}}-\frac{\partial \tilde{K}_{2}}{\partial C_{1}}\right](i+\delta)-\left[r\left(D_{2}^{*}\right)-i\right] \frac{\partial D_{2}^{*}}{\partial C_{1}}\right. \\
& \left.-r^{\prime}\left(D_{2}^{*}\right) D_{2}^{*} \frac{\partial D_{2}^{*}}{\partial C_{1}}-\mu f\left(\hat{z}_{2}\right)\left[\frac{\mathrm{d} \hat{z}_{2}}{\mathrm{~d} D_{2}^{*}} \frac{\partial D_{2}^{*}}{\partial C_{1}}+\frac{\mathrm{d} \hat{z}_{2}}{\mathrm{~d} K_{2}^{*}} \frac{\partial K_{2}^{*}}{\partial C_{1}}\right]+\mu f\left(\hat{z}_{2}\right)\left[\frac{\mathrm{d} \hat{z}_{2}}{\mathrm{~d} \tilde{K}_{2}} \frac{\partial \tilde{K}_{2}}{\partial C_{1}}\right]\right\} \\
& =\beta\left\{\left[\Pi^{\prime}\left(K_{2}^{*}\right)-p(i+\delta)\right] \frac{\partial K_{2}^{*}}{\partial C_{1}}-\left[\Pi^{\prime}\left(\tilde{K}_{3}\right)-p(i+\delta)\right] \frac{\partial \tilde{K}_{2}}{\partial C_{1}}\right. \\
& -\left[r\left(D_{2}^{*}\right)+r^{\prime}\left(D_{2}^{*}\right) D_{2}^{*}-i\right]\left(p \frac{\partial K_{2}^{*}}{\partial C_{1}}-1\right)-\mu f\left(\hat{z}_{2}\right)\left[\frac{\mathrm{d} \hat{z}_{2}}{\mathrm{~d} D_{2}^{*}}\left(p \frac{\partial K_{2}^{*}}{\partial C_{1}}-1\right)\right] \\
& \left.-\mu f\left(\hat{z}_{2}\right)\left[\frac{\mathrm{d} \hat{z}_{2}}{\mathrm{~d} K_{2}^{*}} \frac{\partial K_{2}^{*}}{\partial C_{1}}\right]+\mu f\left(\hat{z}_{2}\right)\left[\frac{\mathrm{d} \hat{z}_{2}}{\mathrm{~d} \tilde{K}_{2}} \frac{\partial \tilde{K}_{2}}{\partial C_{1}}\right]\right\} \\
& =\beta\left\{\left\{\Pi^{\prime}\left(K_{2}^{*}\right)-p\left[r\left(D_{2}^{*}\right)+r^{\prime}\left(D_{2}^{*}\right) D_{2}^{*}+\delta\right]-\mu f\left(\hat{z}_{2}\right)\left[\frac{\mathrm{d} \hat{z}_{2}}{\mathrm{~d} D_{2}^{*}} p+\frac{\mathrm{d} \hat{z}_{2}}{\mathrm{~d} K_{2}^{*}}\right]\right\} \frac{\partial K_{2}^{*}}{\partial C_{1}}\right. \\
& -\left\{\left[\Pi^{\prime}\left(\tilde{K}_{2}\right)-p(i+\delta)\right] p^{-1}-\left[r\left(D_{2}^{*}\right)+r^{\prime}\left(D_{2}^{*}\right) D_{2}^{*}-i\right]\right. \\
& \left.\left.-\mu f\left(\hat{z}_{2}\right)\left[\frac{\mathrm{d} \hat{z}_{2}}{\mathrm{~d} D_{2}^{*}}+\frac{\mathrm{d} \hat{z}_{2}}{\mathrm{~d} \tilde{K}_{2}} p^{-1}\right]\right\}\right\} .
\end{aligned}
$$


Proposition 3 establishes that the first bracketed expression following the last equality is equal to zero. Hence,

$$
\begin{aligned}
\frac{\partial \mathcal{H}_{1}}{\partial C_{1}}= & -\beta p^{-1}\left\{\Pi^{\prime}\left(\tilde{K}_{2}\right)-p\left[r\left(D_{2}^{*}\right)+r^{\prime}\left(D_{2}^{*}\right) D_{2}^{*}+\delta\right]-\mu f\left(\hat{z}_{2}\right)\left[\frac{\mathrm{d} \hat{z}_{2}}{\mathrm{~d} D_{2}^{*}} p+\frac{\mathrm{d} \hat{z}_{2}}{\mathrm{~d} \tilde{K}_{2}}\right]\right\} \\
= & -\beta p^{-1}\left\{\Pi^{\prime}\left(\tilde{K}_{2}\right)-p\left[r\left(D_{2}^{*}\right)+r^{\prime}\left(D_{2}^{*}\right) D_{2}^{*}+\delta\right]-\mu f\left(\hat{z}_{2}\right)\left[\frac{\mathrm{d} \hat{z}_{2}}{\mathrm{~d} D_{2}^{*}} p+\frac{\mathrm{d} \hat{z}_{2}}{\mathrm{~d} K_{2}^{*}}\right]\right\} \\
& -\beta p^{-1}\left\{\frac{\mathrm{d} \hat{z}_{2}}{\mathrm{~d} K_{2}^{*}}-\frac{\mathrm{d} \hat{z}_{2}}{\mathrm{~d} \tilde{K}_{2}}\right\} \\
= & -\beta p^{-1}\left[\Pi^{\prime}\left(\tilde{K}_{2}\right)-\Pi^{\prime}\left(K_{2}^{*}\right)\right]-\beta p^{-1}\left\{\frac{\mathrm{d} \hat{z}_{2}}{\mathrm{~d} K_{2}^{*}}-\frac{\mathrm{d} \hat{z}_{2}}{\mathrm{~d} \tilde{K}_{2}}\right\}<-\beta p^{-1}\left\{\frac{\mathrm{d} \hat{z}_{2}}{\mathrm{~d} K_{2}^{*}}-\frac{\mathrm{d} \hat{z}_{2}}{\mathrm{~d} \tilde{K}_{2}}\right\} .
\end{aligned}
$$

The bracketed expression on the right-hand side of the last inequality is strictly positive, making $\mathcal{H}_{1}$ strictly decreasing in $C_{1}$ :

$$
\begin{aligned}
\frac{\mathrm{d} \hat{z}_{2}}{\mathrm{~d} K_{2}^{*}}-\frac{\mathrm{d} \hat{z}_{2}}{\mathrm{~d} \tilde{K}_{2}} & =-\left\{\Pi^{\prime}\left(K_{2}^{*}\right)-p(i+\delta)\right\}+\left\{\Pi^{\prime}\left(\tilde{K}_{2}\right)-p(i+\delta)\right\} \\
& =\Pi^{\prime}\left(\tilde{K}_{2}\right)-\Pi^{\prime}\left(K_{2}^{*}\right)>0 .
\end{aligned}
$$

When $C_{1}$ is sufficiently large, capital investment becomes unconstrained, i.e., $K_{2}^{*}=\tilde{K}_{2}$, so that $\mathcal{H}_{1}<0$. As $\tilde{K}_{2}$ approaches zero, $\frac{\partial \mathcal{H}_{1}}{\partial C_{1}}$ approaches negative infinity. This implies that as $C_{1}$ approaches its lower bound of $-p(1-\delta) K_{1}, \mathcal{H}_{1}$ approaches infinity. It now follows that, just as in period two, there exists a unique threshold, $\hat{C}_{1}$, that triggers refinancing. When $C_{1}<\hat{C}_{1}$, the firm increases external finance and invests as described in the first part of proposition 3 . When $C_{1} \geq \hat{C}_{1}$, the firm does not increase external finance. If $C_{1}$ is large enough to internally finance the capital stock that is optimal with external finance unchanged at $D_{1}$, then the firm invests as described in the first and second parts of proposition 3. Otherwise, there is under-investment relative to the capital stock described in the first part of proposition 3. 
Finally, $\hat{C}_{1}<\bar{C}_{1}$. To argue that this is the case, notice that if $C_{1} \geq \bar{C}_{1}$, then $\tilde{K}_{2}=K_{2}^{*}$. This, in turn, implies that $\mathcal{H}_{1}\left(\bar{C}_{1}\right)<0$ :

$$
\begin{aligned}
\mathcal{H}_{1}= & \beta\left\{-\left[r\left(D_{2}^{*}\right)-i\right]\left[D_{2}^{*}-D_{1}\right]-\left[r\left(D_{2}^{*}\right)-r\left(D_{1}\right)\right] D_{1}-(1+i) \mu+\mu \int_{\hat{z}_{2}\left(D_{2}^{*}, K_{2}^{*}\right)}^{\hat{z}_{2}\left(D_{1}, \tilde{K}_{2}\right)} f(z) d z\right\} \\
& <-\beta\left\{\left[r\left(D_{2}^{*}\right)-i\right]\left[D_{2}^{*}-D_{1}\right]+\left[r\left(D_{2}^{*}\right)-r\left(D_{1}\right)\right] D_{1}+\mu i\right\}<0 .
\end{aligned}
$$




\section{References}

Almeida, H., M. Campello, and M. Weisbach (2004): “The Cash Flow Sensitivity of Cash," Journal of Finance, 59(5), 1425-60.

Calomiris, C. W., And C. Himmelberg (2002): "Investment Banking Costs as a Measure of the Cost of Access to External Finance," Manuscript, Columbia University.

Cummins, J. G., K. A. Hassett, and S. D. Oliner (2003): "Investment Behavior, Observable Expectations, and Internal Funds," Manuscript, Board of Governors of the Federal Reserve System.

Donaldson, G. (1984): Managing Corporate Wealth. Praeger, New York.

ERICKSON, T., AND T. M. Whited (2000): "Measurement Error and the Relationship Between Investment and q," Journal of Political Economy, 108(6), 1027-57.

Gross, D. (1995): “The Investment and Financing Decisions of Liquidity Constrained Firms," Manuscript, MIT.

HUBBARD, R. G. (1998): “Capital-Market Imperfections and Investment,” Journal of Economic Literature, 36(1), 193-225.

Kim, C.-S., D. C. MAUER, ANd A. E. Sherman (1998): "The Determinants of Corporate Liquidity," Journal of Financial and Quantitative Analysis, 33(3), 335-59.

Opler, T., L. Pinkowitz, R. Stulz, and R. Williamson (1999): “The Determinants and Implications of Corporate Cash Holdings," Journal of Financial Economics, 52(1), $3-46$.

Smith, C. W. (1977): "Alternative Methods for Raising Capital: Rights Versus Underwritten Offerings," Journal of Financial Economics, 5(3), 273-307. 